\title{
Mental Health Education of the Minority Engineering College Students
}

\author{
Huanchang Qin ${ }^{1, a}$, Mengzhen Chen ${ }^{1, b}$, Meisuo Wang ${ }^{2, c^{*}}$ \\ ${ }^{1}$ School of Information Engineering, Baise University, Guangxi 533000, China \\ ${ }^{2}$ Health clinic, Baise University, Guangxi 533000, China \\ Corresponding author: Meisuo Wang, Health clinic, Baise University \\ aqin8638@163.com, b43540944@qq.com, c13097765363@163.com
}

Keywords: The minority, engineering students, mental health education.

\begin{abstract}
Mental health education of the minority engineering college students still faces lots of problems. Those problems have prevented the further improvement of minority engineering students' personal qualities Thus, it is imperative to build mental health education model of the minority engineering college students.
\end{abstract}

\section{Introduction}

At present, research on mental health college students in engineering has been conducted. It is found that the incidence rates of anxiety, depression and other related mental illnesses are apparently higher than other general institutions. And rural students are in the poorer mental health status, compared to urban college students. The curriculum of engineering college generally contains two main parts-foundation courses and specialized courses. Generally speaking, specialized courses are usually scheduled after foundation courses. Throughout the engineering colleges, specialized courses are usually more difficult and duller than foundation courses. Consequently, students are less interested in studying specialized courses. Without the motivation, study pressure seems to be doubled. In the whole process of learning, students will faces a lot of problems with mental and physical growth, including emotional problems and difficulties in employment decisions. These problems represent the pressure which students have to bear. And rapidly growing pressure often leads to students' mental health problems. As a result, corresponding measures are required to be taken in time for mental health education of engineering colleges, considering the mental health problems of their current students [1].

\section{Analysis on the mental health problems of current minority engineering college students}

According to the survey in engineering colleges, students tend to have two obvious performances in the face of difficulties. One is facing difficulties without fear and staying positive attitude to overcome difficulties. Another is showing a negative attitude, such as being afraid of difficulties and fighting against difficulties. And the proportion of people with negative attitude is significantly higher than that with positive attitude. Students with negative attitude usually have the following symptoms at the school: First, they will do things without goals, usually being passive to accept goals instead of taking initiative to set goals for themselves; secondly, they are lack of driving force, with the general symptoms of being extremely lazy and not willing to do anything; thirdly, they are indulged in enjoyment and pleasure, leading to the tiredness of study. They are easily to be influenced by the negative moods of other students to become pessimistic and depressed. In the end, 
they will be unwilling to communicate with people, being more self-abased and feeling lonely. Therefore, it can be concluded that mental health problems of engineering college students are mainly ascribed to the following three aspects:

Rapidly-increasing population. Currently, the number of students having mental health problems has been constantly growing in Chinese engineering colleges. Problems of mental disorders are getting more severe. The lack of mental health care will usually cause mental health crisis. Nowadays, the number of students of engineering colleges is much more than that of liberal arts colleges. Besides, sexual proportion is seriously imbalanced in the engineering colleges. The influences of all of those comprehensive factors are often clearly reflected in the newly enrolled students.

Complex factors of mental health problems. Mental health crisis phenomena generally occur when students are faced with academic pressure, emotional pressure, employment stress and family pressures. A survey in Shanghai has investigated the reasons of college students' suicides. The data displays that 33\% students suicide for academic pressure; $28 \%$ for bad interpersonal relationship; $22 \%$ for emotional dispute; $11 \%$ for spiritual problem; the rest $6 \%$ for physical reason.

Out of control to mental health crisis. When mental health crisis occurs, individual students will be in an extremely nervous mental state. If this mental state lasts for a long time and cannot be effectively alleviated, the tragedy of suicide may happen. As what is indicated in related survey, there are student suicide cases in many colleges in Nanjing since 2007. Among them, several colleges even have more than one suicide case.

In a word, the minority students in engineering universities in China are not in an optimistic situation. Under complex and changing social environment, mental health problems of the minority engineering students are emerging constantly. Different kinds of measures should be taken to effectively help the minority engineering students resolve their mental health problems [2].

\section{Strategy to construct mental health education model for the minority students in engineering colleges}

Relevant departments need to attach great importance to the mental health education of the minority students in engineering colleges. Based on the long-term practical research, construction of mental health education model for the minority students in engineering colleges can be executed from the following aspects. These aspects will effectively help students solve mental health problems and promote their further development.

Guidance for students' extracurricular science and technology activities. Engineering students can also participate in extracurricular academic science and technology activities, apart from foundation courses and specialized courses. Known as the second class, academic science and technology activities are beneficial to the development of students' learning ability. The minority college students in engineering are able to show their talents and fully excavate their potential by taking part in this kind of activities. In order to enrich students' extracurricular lives, league organizations at all levels are supposed to actively develop campus culture and cooperate with each other under the guidance of campus culture. Developing campus culture should use programs as carrier. By taking full advantage of league organizations and clubs on campus, they will become the communication bridge between campus culture and student groups. In addition, students can be guided to positively accept mental health education, contributing to the development of campus culture on mental health. At the same time, good campus culture will provide an excellent study environment for students. The current campus cultural activities are often program-based. In the 
constantly promoting process, activity form of "league organizations being responsible for the mutual communication and clubs as well as student union being in charge of detailed implementation" is required to be set up. Meanwhile, the form of mental health programs needs to be enriched. It is necessary for colleges to advocate various student organizations at all levels to be actively involved in mental health education. "Large-scale activities need to be promoted in the college; schools are in charge of medium-scale activities; and small-scale activities should be carried out regularly and be club-based". Mental health education is an indispensable part in students' learning process. Engineering colleges are supposed to attach more importance to students' mental health and introduce mental health education when cultivating students' three views. Students will realize the importance of mental health education, with the relevant added credits in training program. It is also possible for teachers to actively guide students to take part in mental health education through daily teaching activities. Contemporarily, foreign countries have acquired mature achievements in mental health education. It is beneficial to learn from their successes and utilize it in accordance with the actual situation of our own [3].

Strengthening the cultivation of students' innovation ability and practical ability. Nowadays, quality education is a vital education mode for the cultivation of students' comprehensive ability. During the process of implementing quality education in engineering colleges, cultivation of students' individual comprehensive abilities should be highly valued. Besides, construction of campus culture is required to be strengthened to put quality education into practice. Eventually, students are provided with a good growing environment to become socially useful talents. Innovation and practical abilities are the important measurements of students' comprehensive abilities. Therefore, these two abilities should be emphasized in the construction of quality education and campus culture. Talents cultivation goal needs to be combined with the actual needs of social development. On the basis of stable development, it should pay more attention to innovation. Besides, it should encourage the minority engineering students to actively carry out scientific innovation activities to raise their awareness of innovation. Colleges should provide labor and material resources for scientific innovation activities. By holding relevant practical activities, students are capable of putting their knowledge in practice, becoming truly socially useful scientific talents. For colleges, they will gain more academic achievements and raise their reputation by improving students' awareness of innovation and cultivating students' scientific research abilities. Consequently, colleges can better cultivate aggressive and innovative students.

Encouraging students to participate in the youth volunteer activities. Youth volunteer activity allows the minority engineering students to participate in the construction of socialist spiritual civilization. The minority engineering students are able to improve themselves in the practice, thus continuously raising their ideological realm. In the construction of socialist spiritual civilization, the youth volunteer activity is one of the significant approaches for the minority engineering students' participation. Being the youth volunteers, students are capable of practicing on their own, and enhancing their comprehensive abilities in practice. Besides, it also teaches students to appreciate dedication and gradually correct their thoughts. Therefore, league organizations at all levels and various clubs in school need to pay more attention to the youth volunteer activities. With their practical support, youth volunteer activities can be carried out smoothly. In addition, a sound volunteer management system should be set up to record basic information, attendance and performance of volunteers. It should enable students to actively participate in those activities. With the propaganda of volunteer activities on network, traditional campus newspapers and posters, colleges need to instruct the students to set up good qualities to serve the community and selflessly 
dedicate to the society, being the good examples of learning from Lei Feng. Beyond that, students are capable of combining their professional knowledge with volunteer activities to put theories into practice. This win-win situation will both benefit the society and students to add new vitality to campus culture.

Constructing psychological consultancy organization. In order to effectively prevent students from different mental health problems, engineering colleges should add mental health education to the education content of the minority engineering students. Through mental health education, students can constantly improve their mental health levels. It is essential for engineering colleges to learn from the management methods of league organizations or clubs, and establish corresponding appropriate mental health counseling department. With sufficient fund, professional psychological consultants can be recruited to provide students with counseling services. Besides, they are able to offer more options to students though the Internet, including establishing counseling platform or using forum like BBS and post bar. The mental counseling departments are required to be professional to do excellent counseling work and to effectively solve students' mental health problems. It is helpful to give mental health lectures for different grades of students. Thus, colleges will create a good learning environment for mental health education. With the establishment of student mental health counseling system, mental problems of students can be discovered and resolved in time, and be prevented in advance [4].

Constructing mental health education team. Only with professional team of mental health education, can the level of mental health education be improved in colleges. A professional team of mental health education plays a vital role in the whole system of mental health counseling. Engineering colleges need a professional team of teachers who are familiar with mental education. These teachers are required to not only have excellent professional qualities, but also have a wealth of working experience. For school teachers who have worked on counseling department, their professional qualities need to be improved. According to the relevant Chinese regulations, mental health certificate is necessary for teachers to be engaged in mental education. So colleges need to check out whether the specific vocation requires any qualifications. In college, students' class teachers and instructors also have important functions in students' mental health education. Consequently, counselors and class teachers are supposed to have some mental health knowledge as well. Certain training will contribute to the enhancement of their abilities in this field. Through the daily contact with students, they will be competent to solve problems according to the actual situations of the students. Thus, students can gradually improve their mental health knowledge. For school students in different grades, mental health education should be conducted respectively. Different mental health courses are aimed to students in different ages and different cognition levels. Eventually, students will truly solve their mental health problems, thus cultivating sound personalities and excellent mental qualities before they enter into the community.

Constructing civilized and progressive campus environment. Mental health problems of the minority engineering students have troubled engineering colleges for many years. It is a long an hard process to the solve the minority engineering students' mental health problems. Therefore, for the mental healthy growth of the minority engineering students, engineering colleges should vigorously build their own campus culture, creating a favorable environment for students' development. Based on that, scientific and cultural activities which engineering students are specialized can be held to arouse their interests. Being involved in those activities, students are able to enhance their mental qualities to be strong-willed. Engineering colleges need to respond positively to the quality education of China and obey the national laws and regulations. To provide 
students with excellent education environment, classes and grades in colleges should be arranged to compete with each other to construct civilized classes. This method can be applied to student

dormitories as well. Positive competition is conductive to solidarity and mutual support of classmates and roommates. If students are friendly and sincere to each other, the whole college will have the positive environment. The mental health of every student in engineering colleges will be developed.

Construction of the minority engineering students' mental health education should be conducted in a civilized and progressive campus environment. And mental health counseling organization and teachers team of mental health education should be built on this basis. In the end, mental health education problem will be further solved to promote the overall development of students.

\section{Conclusion}

Mental health education of the minority engineering students should be executed from reality. With innovative education mode, mental health problems of the minority engineering students are going to be effectively solved in the real sense. More talents with high qualities can be cultivated for the society.

\section{Acknowledgement}

The work was supported by Research Center of the Spirit of Former Revolutionary Areas of Key Research Base for Humanities and Social Sciences in Guangxi; "Reform and Exploration of Basic Experiment Teaching for Electronic Major in Newly-Established Universities”, 2013 Educational Reform Project of Higher Education in Guangxi (Grant Number: 2013JGB234).

\section{References}

[1] Fumin Fan, Jianzhong Wang, Current College Students' Mental Health Tutorial, sixth ed., Wuhan University Press, Wuhan, 2006.

[2] Deng Hu, Xiaojing Zhang, Shufeng Wen, Theories and practice of setting college students' mental health elementary course, Chinese Higher Education, 3 (2010) 23-24.

[3] Wells J, Barlow J, Stewart-Brown S, A systematic re-view of universal approaches to mental health promotion in schools, Health Education, 103(4) (2003)197-220.

[4] Wanjin Meng, Positive mental health education, Education Research, 340 (5) (2008) 41-45. 